\title{
Co-ordination of physics journals in Europe
}

\section{J. de Boer}

In the discussions which stimulated the creation of the European Physical Society, the questions related to publication problems, in particular to the physics journals in Europe, played a central role. It was certainly not the main problem. The EPS was in the first place the result of the irreversible movement of the European community towards unification. The creation of a European organization of physicists was the formal expression of the strong conviction that collaboration between scientists contributes tremendously towards strengthening the relations between people of all European countries, and that promoting this unification is an inescapable historical necessity.

However, development of uncorrelated publication activities in Europe in the last ten years has demonstrated the absence of any organization and co-ordination. A large number of specialized journals was added to a broad spectrum of journals already in existence, without any guiding principle other than the immediate need of particular groups of physicists for publication facilities, and the connected business considerations. As a result, we have at present an extremely large variety of different types of physics journals: the old academy journals, national journals, specialized international journals, review journals, letter journals, etc. Many of them are excellent but there are others which do not really satisfy scientific standards.

In general, physicists are convinced of the urgent need to arrive at a European authority for publications which co-ordinates existing and newly developing activities, which improves the scientific level, which achieves standardization and thus promotes a unified publication system.

\section{Present Situation}

The present situation has its roots in the last century, when some active academy journals, society journals, and a variety of good commercial journals, formed a spectrum of physics journals, mostly published in Europe, in which practically all publications appeared. Since then some journals have developed, some have weakened, some have disappeared completely, but many others have been created. The number of well-known journals publishing only primary articles devoted to pure and applied physics, is about 65, publishing about 100000 pages per year. (Journals on physical chemistry, chemical physics, engineering, astronomy, geophysics, etc., and several other technical applied journals, are not included in this figure. Also the USSR journals and Academy journals are not counted.) 18 journals (about 30000 pages per year) are produced by physical or other professional Societies, the other $70 \%$ are published by various European publishing houses many of which are well-known and have a longstanding tradition in valuable physics publications.

It is interesting to compare these figures with those in the USA. The American Institute of Physics has for the last 50 years been able to concentrate most activities in physics publications. The AIP now publishes 16 journals, with about 70000 pages per year.

(There are of course many more journals than those mentioned: in a recent publication the AIP quotes that in 1965 there existed 316 journals in Europe and 93 in the USA (500 in the whole world), which contributed at least two abstracts per year on physics in Physics Abstracts. This includes, however, many journals in other fields which occasionally publish physics articles, and which should not be counted as physics journals.)

\section{EPS Publication Committee}

At the meeting of the Steering Committee, which took place in Geneva on 30 January 1968, a Subcommittee for publications was created which worked out, at this meeting and at subsequent meetings in Prague and Geneva, the broad outline of EPS policy in these matters.

The main conclusion is that in view

\begin{tabular}{|c|c|c|c|c|c|c|}
\hline \multirow{2}{*}{$\begin{array}{c}\text { Physics Journals } \\
\text { in Europe }\end{array}$} & \multicolumn{2}{|c|}{ Professional Societies } & \multicolumn{2}{|c|}{ Publishers } & \multicolumn{2}{|c|}{ Total } \\
\hline & $\begin{array}{l}\text { Number } \\
\text { of Journals }\end{array}$ & $\begin{array}{l}\text { Number } \\
\text { of Pages/Year }\end{array}$ & $\begin{array}{l}\text { Number } \\
\text { of Journals }\end{array}$ & $\begin{array}{c}\text { Number } \\
\text { of Pages/Year }\end{array}$ & $\begin{array}{l}\text { Number } \\
\text { of Journals }\end{array}$ & $\begin{array}{c}\text { Number } \\
\text { of Pages/Year }\end{array}$ \\
\hline General Physics & 10 & 13100 & 17 & 13300 & 27 & 26400 \\
\hline Special Fields & 3 & 10700 & 18 & 42400 & 21 & 53100 \\
\hline Applied Physics & 5 & 6100 & 12 & 12300 & 17 & 18400 \\
\hline Total & 18 & 29900 & 47 & 68000 & 65 & 97900 \\
\hline
\end{tabular}


of the existing situation in Europe it would be unrealistic to try to imitate the AIP system. It has been decided not to attempt to create a whole new set of EPS physics journals : the EPS will try to play a co-ordinating role between existing good physics journals, and to achieve, through negotiations with interested societies and publishers, a satisfactory and co-ordinated publication scheme under the auspices of the EPS, in which all good journals, satisfying certain essential criteria, can participate.

The general procedure to be followed and the criteria to be satisfied by those journals which wish to be incorporated in the scheme of European journals under the sponsorship of the European Physical Society, were drawn up by the Publication Committee and approved by the Executive Committee. The Executive Committee also created the EPS Publication Board in the first instance to deal with all matters connected with this EPS publication scheme. This Publication Board advises the Executive Committee which takes the decisions.

Following proposals from the participating Physical Societies, the Executive Committee nominated the following for the Publication Board: J. Depireux (Belgium), J. Vlachy (Czechoslovakia), E. Richter (Federal Republic of Germany), L. Laitinen (Finland), J. Friedel (France), L. Cohen (Great Britain), G. Turchanyi (Hungary), G. Toraldo di Francia (Italy), R. Nilsson (Sweden), K.P. Meyer (Switzerland), I. Lechkovcev (USSR), I. Slaus (Yugoslavia), E. Ascher (for Europhysics News) and J. de Boer (Netherlands) - Chairman.

\section{Criteria}

1) The language used in the journal should be understood by a large group of scientists in Europe : it has been agreed that a journal sponsored by the EPS should publish either in three or four languages out of English, French, German and Russian.

2) The journal should be under the direction of an Editorial Committee which contains several scientists from European countries other than the country in which the journal is published. Six from other countries was considered to be a guiding figure, but for originally national journals which will probably keep a more regional European character, this figure may be too large. The Editor-in-chief and the composition of the Editorial Committee should be subject to the approval of the EPS and one scientist in the Editorial Committee should act as a representative of the EPS.
3) Great value is attached to a good refereeing system which is considered indispensable for maintaining a high scientific standard. The Editorial Committee should play an essential role in establishing an efficient refereeing system. The international composition of the Editorial Committee should also safeguard the European character of the journal so that there is no bias either in favour of scientists from one particular country or against scientists from other countries.

4) The publication time should be a point of continued attention.

5) In principle, there should be no page charge. Arguments can be advanced for and against page charges but the situation in Europe is that page charges are almost completely absent. Under these conditions it is more practical to require no page charge in any of the journals sponsored by the EPS. In those cases where this requirement is not yet satisfied, some kind of a transition measure will be needed.

6) Last, but not least, the Editor should be willing to accept several measures to achieve more uniformity in technical aspects, such as size and front cover make-up, and rules for preparation of manuscripts. An EPS Publication Style Manual should be prepared in collaboration with the co-operating journals.

\section{Europhysics Journals}

All journals which satisfy the criteria and which are admitted to the EPS publication scheme may carry the indication "Europhysics Journal, sponsored by the European Physical Society" on their front cover together with the EPS emblem.

It is obvious that establishing this co-ordinated set of Europhysics Journals will take time, but the EPS wants to proceed as fast as possible. A procedure and a time schedule have been drawn up for admitting journals to the EPS publication scheme, which might make it possible to start in January 1970 with a limited set, gradually extending in subsequent years.

Co-ordination of physics journals in Europe is only one of the fields of activity on which the EPS has to concentrate. Questions related to making available the primary information to interested scientists, the retrieval system, the problem of digestion of primary information in the form of review articles, the possible creation of "Information Centres", etc. are all problems needing considerable further study. This is certainly one of the future tasks of the EPS.

\section{Meetings}

Notification of the following meetings to be held up to the end of September 1969 has been received. The meetings announced up to the beginning of August are in addition to those advertised in the previous issue of Europhysics News. The meetings are listed - date; title, venue; contact for information.

31 MARCH - 2 APRIL

International Symposium on Electrohydrodynamics

Cambridge, Mass., USA

J.R. Melcher, Dept. of Electrical Eng.

MIT, Cambridge, Mass. 02139

9- 11 APRIL

2nd European High Pressure Research Conference

Bonn, Federal Republic of Germany

J. Lees, Standard Telecommunication

Laboratories Ltd., London Road, Harlow, Essex, UK

$15-18$ APRIL

1969 Intermag Conference

Amsterdam, Netherlands

Th. Holtwijk, Philips Research Laboratories, Eindhoven

6 - 9 MAY

International Topical Conference on Nuclear

Track Registration in Insulating Solids and Applications

Clermont-Ferrand, France

Jourentra, Faculté des Sciences,

34, av. Carnot, 63 - Clermont-Ferrand

26 - 30 MAY

15th International Symposium of Spectroscopy

Madrid, Spain

Colloquium Spectroscopium Internationale,

Serrano 119, Madrid 6

29 - 30 MAY

Physics of Low-Energy Positrons and of Positronium

Saclay, France

R. Paulin, Secretary of the Conference, P.O.B. 6, Gif-sur-Yvette

2-6 JUNE

Radiation Damage in Reactor Materials

Vienna, Austria

C. Lathwell, Ministry of Technology, Millbank Tower, London SW 1, UK

3-5 JUNE

Microelectronics

Eastbourne, UK

Conference Secretariat, IEE,

Savoy Place, London WC 2

25 JUNE - 1 JULY

International Conference on Elementary Particles Lund, Sweden

Miss E.W.D. Steel, CERN,

1211 Geneva 23, Switzerland

30 JUNE - 2 JULY

16th International Astrophysical Colloquium

Liège, Belgium

Mme D. Bosmann-Crespin, Institut d'Astrophysique, Cointe-Sclessin

30 JUNE - 4 JULY

From Theoretical Physics to Biology

Versailles, France

Prof. Marois, Institut de la Vie,

89 boulevard Saint-Michel, Paris

30 JUNE - 12 JULY

Summer School and Symposium on Molecular Movements in the Liquid Phase

Menton, France

M. Bratos, Centre de Mécanique Ondulatoire Appliquée, 23, rue du Maroc, Paris-19e

8- 12 JULY

International Conference on the Three-

Body Problem

Birmingham, UK

Administrative Officer, Dept. of Physics

P.O.B. 363 , Birmingham 15

$14-15$ JULY

Informal Meeting on Ultra-short Pulses and their Interaction with Matter 